Article

\title{
Exploring Opportunities and Challenges of Artificial Intelligence and Machine Learning in Higher Education Institutions
}

\author{
Valentin Kuleto $^{1}$, Milena Ilić ${ }^{1, *(\mathbb{D})}$, Mihail Dumangiu ${ }^{2}$, Marko Ranković $^{3}$, Oliva M. D. Martins $^{4} \mathbb{D D}$, Dan Păun $^{2}$ \\ and Larisa Mihoreanu 5
}

\section{check for}

updates

Citation: Kuleto, V.; Ilić, M.; Dumangiu, M.; Ranković, M.; Martins, O.M.D.; Păun, D.; Mihoreanu, L. Exploring Opportunities and Challenges of Artificial Intelligence and Machine Learning in Higher Education Institutions. Sustainability 2021, 13, 10424. https://doi.org/10.3390/ su131810424

Academic Editor: Gisela Cebrián

Received: 20 August 2021

Accepted: 16 September 2021

Published: 18 September 2021

Publisher's Note: MDPI stays neutral with regard to jurisdictional claims in published maps and institutional affiliations.

Copyright: (c) 2021 by the authors. Licensee MDPI, Basel, Switzerland. This article is an open access article distributed under the terms and conditions of the Creative Commons Attribution (CC BY) license (https:/ / creativecommons.org/licenses/by/ $4.0 /)$.
1 Information Technology School ITS- Belgrade, LINK Group Belgrade, Faculty of Contemporary Arts Belgrade, University Business Academy in Novi Sad, 11000 Belgrade, Serbia; valentin.kuleto@its.edu.rs

2 Faculty of Physical Education and Sport, Spiru Haret University, 030045 Bucharest, Romania; dumangiu.mihail@spiruharet.ro (M.D.); ush-efs_paun.dan@spiruharet.ro (D.P.)

3 Faculty of Information Technology and Engineering, University Union Nikola Tesla, 11080 Belgrade, Serbia; marko.rankovic@fiti.edu.rs

4 Instituto Politécnico de Bragança, IPT, 5300-253 Bragança, Portugal; oliva.martins@ipb.pt

5 Faculty of Administration and Public Management, Bucharest University of Economic Studies, 010374 Bucharest, Romania; dr.mihoreanu@gmail.com

* Correspondence: milena.ilic@its.edu.rs

\begin{abstract}
The way people travel, organise their time, and acquire information has changed due to information technologies. Artificial intelligence (AI) and machine learning (ML) are mechanisms that evolved from data management and developing processes. Incorporating these mechanisms into business is a trend many different industries, including education, have identified as game-changers. As a result, education platforms and applications are more closely aligned with learners' needs and knowledge, making the educational process more efficient. Therefore, AI and ML have great potential in e-learning and higher education institutions (HEI). Thus, the article aims to determine its potential and use areas in higher education based on secondary research and document analysis (literature review), content analysis, and primary research (survey). As referent points for this research, multiple academic, scientific, and commercial sources were used to obtain a broader picture of the research subject. Furthermore, the survey was implemented among students in the Republic of Serbia, with 103 respondents to generate data and information on how much knowledge of AI and ML is held by the student population, mainly to understand both opportunities and challenges involved in AI and ML in HEI. The study addresses critical issues, like common knowledge and stance of research bases regarding $\mathrm{AI}$ and ML in HEI; best practices regarding usage of AI and ML in HEI; students' knowledge of AI and ML; and students' attitudes regarding AI and ML opportunities and challenges in HEI. In statistical considerations, aiming to evaluate if the indicators were considered reflexive and, in this case, belong to the same theoretical dimension, the Correlation Matrix was presented, followed by the Composite Reliability. Finally, the results were evaluated by regression analysis. The results indicated that $\mathrm{AI}$ and ML are essential technologies that enhance learning, primarily through students' skills, collaborative learning in HEI, and an accessible research environment.
\end{abstract}

Keywords: artificial intelligence; machine learning; e-learning; higher education institutions

\section{Introduction}

Artificial intelligence (AI) and machine learning (ML) advancements help people go beyond classic computers to simulate and surpass human intelligence. The development of such technologies has already significantly altered the educational world, giving students new skills and providing a collaborative learning environment in the HEI with great implications for the near future [1,2]. Data show that the Republic of Serbia operates 18 universities, of which nine are public, and the rest are privately owned [3]. No 
matter their ownership, the universities' curriculums are trying to follow the latest trends in education, covering most of the job market requirements and harmonising with the technological advancements. Thus, higher education in Serbia is progressively developing for the general benefit of students, academics, and society to create a resilient environment of knowledge and growth [4]. The state of the education system in Serbia and traditional education concepts in most cases make it easier for modern educational institutions to gain a competitive edge. The main competition refers to cost structure, branding, quality of managerial activities and service offerings, the knowledge dissemination network, intellectual property, and final results rendered to the labour market. Education for modern HEI and EdTech companies means outperforming the competition between significant competitors, facing the market needs, and gaining leadership positions based on vivid knowledge and experience and marked by foresight and imagination. Resilient education refers to realistic environmental, social, and governance investments to ensure that most of the benefits and results awarded in the future are accepted by individuals and society.

Most reputable high education institutions have understood that AI and ML represent the present and future in both education and the world's progressive development. Such technologies provide an interactive and advanced educational experience to their students. The results are impressive: 65 per cent of universities in the United States of America support AI- and ML-assisted learning. Moreover, these systems provide valuable assistance to teachers and lecturers in the best schools, facilitating and improving learning in various ways. For example, estimates indicate that AI in education in the United States increased by 47.5 per cent between 2017 and 2021 [5].

Good examples of AI adoption come from the University of Derby, which introduced a system that monitors data to predict when students are likely to drop out to signal timely interventions and Deakin University in Australia, employing IBM Watson to respond to student inquiries [6]. In addition, Professor Ashok Goel at Georgia Tech developed Jill Watson, an AI teaching assistant that students can interact with [7].

Kumar found that AI and ML are improving the security and efficiency of the institution, providing a peaceful, flexible, and accessible computing environment for research and developing skills among students, and a collaborative learning environment in the HEI reinforces the importance of AI and ML to enhance customised learning [8].

The problem statement of the research is how to ascertain the current state of artificial intelligence in higher education, how to ascertain the benefits and drawbacks of artificial intelligence in higher education, and what recommendations exist on how to seize opportunities and overcome challenges to give to HEI. The main research questions that this study addresses are:

- What are the significant opportunities that HEI can accept if they implement AI and ML technologies?

- What are the significant challenges that HEIs face while implementing AI and Ml technologies?

Regarding the concept of the paper and its organisation, this is an original research paper for which the IMRAD model was used to present the theoretical and empirical basis of the research. Considering that IMRAD is the most prominent norm for an original research type structure, we did not choose the PRISMA model. However, the PRISMA model has its values but is presumed to be more appropriate for systematic reviews and meta-analyses.

The motivation for the research lies in the fact that the authors of this article have been individually involved in the development processes that take place in education in their countries for decades. For example, three authors from the Republic of Serbia are developing formal and non-formal education in the Republic of Serbia. In addition, they have initiated the implementation of AI and ML technologies in educational institutions in which they are employed or which they (privately) own.

Additionally, the lack of research in the field of usage of AI and ML on university students (in total), especially in the Republic of Serbia, is the primary motive for this 
research and its added value. As the use of AI and ML technologies is still in its infancy in many countries in the field of higher education, we are convinced that the results of this work will be of great importance for broad international interest, especially for low- and middle-income countries and applications and not only for the local application.

This paper uses document analysis (literature review) to collect qualitative data and knowledge acquirements. The document analysis process adopted the style of the following model: accessing relevant documents, creating an organisational chart, confirming document authenticity, and finding document content [9].

Based on this grounded background, we designed a survey applied in Serbia, in the Information Technology School ITS-Belgrade, on 103 students. Their opinions were coded and analysed through a correlation matrix between variables, a composite reliability analysis, and a regression model in the end that emphasised the opportunities and challenges brought by AI and ML in HEI.

Artificial intelligence has the potential to respond to a number of social and educational needs for HEI and students. The research results showed that AI and ML are technologies that improve the safety and efficiency of the institution and contribute to the learning and teaching process. In this fact lies the importance of this study.

\section{Literature Review}

Thanks to AI and ML concepts and platforms, many educational (teaching and learning) issues can be addressed as well as organisational ones. Thus, critical concepts of the paper refer to artificial intelligence, machine learning, e-learning and higher education. Acronyms of major importance are addressed in Table 1.

Table 1. Acronyms/abbreviation table.

\begin{tabular}{|c|c|c|}
\hline Term & Acronyms & Definition \\
\hline Artificial intelligence & AI & $\begin{array}{l}\text { "the theory and development of computer systems able to } \\
\text { perform tasks normally requiring human intelligence, such } \\
\text { as visual perception, speech recognition, decision-making, } \\
\text { and translation between languages." [10] }\end{array}$ \\
\hline Machine learning & ML & $\begin{array}{c}\text { "Machine learning is a branch of AI and computer science } \\
\text { which focuses on the use of data and algorithms to imitate } \\
\text { the way that humans learn, gradually improving } \\
\text { its accuracy." [11] }\end{array}$ \\
\hline E-learning & EL & $\begin{array}{c}\text { "Is the acquisition of competencies, knowledge, and skills } \\
\text { through electronic media, such as the Internet or a } \\
\text { company Intranet." [12] }\end{array}$ \\
\hline Higher education & $\mathrm{HE}$ & $\begin{array}{l}\text { "education at universities or similar educational } \\
\text { establishments, especially to the degree level." [10] }\end{array}$ \\
\hline Higher education institution & HEI & $\begin{array}{l}\text { "organisations providing higher, post-secondary, tertiary, } \\
\text { and/or third-level education." [13] }\end{array}$ \\
\hline
\end{tabular}

\subsection{ML and AI: Distinct but Complementary Concepts}

\subsubsection{Deep Learning}

Deep learning (DL) techniques are based on multi-neuron architectures to accomplish a learning task where neurons are connected to the input data via a loss function to update their weights and maximise the fit to the inbound data [14].

Reinforcement learning is a mathematical framework for experience-driven, autonomous learning, where agents directly interact with the environment, modifying its efficiency through trial-and-error to optimise the cumulative reward without requiring labelled data. The essential tools in reinforcement learning are policy search and value function approximation [15].

\subsubsection{Artificial Intelligence}

AI is a field of study that focuses on the artificial replication of human intelligence's cognitive abilities to create software or machines capable of performing tasks typically 
carried out by humans [13]. The term "artificial intelligence" is used, according to Russell and Norwig, "when a machine mimics the cognitive functions that humans associate with other human minds, such as learning and problem-solving" [16]. Because ML is not the same as AI, it is necessary to distinguish between the two. There are numerous examples of how AI is being used in the business world. Since 2015, Google has been employing its RankBrain AI system (Google, Mountain View, USA) for advertising purposes, including chatbots, data analysis, product recommendation, and dynamic pricing, among other applications. In addition, the term "artificial intelligence" is frequently used to refer to algorithms that drive automatic processes through ML and use robotics and rules-based systems to predict outcomes. Last but not least, AI, like big data, is something that many entities will unconsciously use as an integral part of a tool or application. The outcome of this fact is far more critical than the technology that aids in its achievement [17].

A significant impact is being made by ML and AI on the evolution of many economy and education sectors and the overall quality of people's lives. ML is one of the most critical areas that can be used to detect cyber-attacks on the Internet of Things, and it is becoming increasingly important. ML is also capable of identifying sophisticated attacks because of the use of in-depth, knowledge-based techniques. The lack of publicly available and regularly updated data sets, on the other hand, is the most severe problem when it comes to IoT security [18].

AI has its evolution path [19]. AI has developed from ML to deep learning to applied AI. A machine's ability to learn from experience, adapt to new inputs, and perform specific tasks without human intervention is enabled by AI built into the machine. For example, face recognition, speech recognition, chess game victory, and other similar functions are possible. AI has been around since the 1950s. However, it is currently experiencing the most significant amount of application due to the explosion in IoT data, fast connectivity, and high-performance computers that has occurred recently. A variety of statistical and computational techniques are currently employed in AI research and development.

The AI subfield of ML identifies patterns and anomalies in data from intelligent sensors and devices without explicitly programmed where to look for them. The algorithms used by ML algorithms "learn" how to provide more accurate results as time progresses. As a result, ML outperforms traditional business intelligence tools to provide operational predictions that are several times faster and more accurate than those provided by rules- and schedulebased approaches. AI is a necessary complement to the Internet of Things thanks to technologies, such as deep learning, computer vision, natural language processing, and ML in time-tested prediction or optimisation, among other things [19].

\subsubsection{Machine Learning}

In itself, ML is a complex area whose tasks require considerable time for execution, i.e., implementation. Therefore, efforts are actively being made, and initiatives are being implemented to optimise the execution time of the processes related to the ML context [20]. Providers in this category offer computer clusters that use public cloud suppliers, such as Amazon EC2, Rackspace, and others. In addition, a predefined piece of statistics software is installed, the preferred packages being the R system, Octave, or Mapple.

This solution offers its customers scalable, high-performance cloud resources, relieving them of unnecessary obligations to install and manage their clusters. Cloudnumbers.com uses Amazon EC2 as a provider to set up computer clusters with a preinstalled piece of scientific data management software, such as the R system, Octave, or Mapple. In addition, a web interface is designed to enable customers to reap many benefits. For example, digital algorithmic applications and impact were evidenced to improve medical care for patients [21,22].

The option to create one workspace and to configure and monitor clusters is available. It is also possible to transfer data sets or connect to public databases. In addition to the cloud service provider's default functions, cloud numbers offer high-security standards, providing secure encryption for data transmission and storage. In general, the 
High-Performance Computing (HPC) platform in the cloud is simple to organise and maintain. CloudStat is the development environment integrated into the cloud. It is built based on $\mathrm{R}$ systems, and its functionalities are presented through the two types of the user interface: a console (for experienced users in the $\mathrm{R}$ language) and the applications (designed as an interface for the users who have no prior knowledge of programming in the R language) [23]. Opani offers services like Cloudnumbers.com's but further helps customers adjust their cluster size to their needs: the size of data and the data processing timeframe. It uses Rackspace's infrastructure and supports environments, such as the $\mathrm{R}$ system, Node, and Python, bundled with maps/reductions, visualisation, security, and version control. In addition, the results of the data analysis process, the dashboard in Opani, can easily be visualised and shared from computers or mobile devices [24].

ML is an extensive field, but ML tasks can be significantly accelerated with the cloudcomputing paradigm. Accordingly, even popular statistical tools, such as R, Octave, and Python, have migrated to the cloud environment. Today, the most significant number of cloud service providers offer the benefits of ML, including significant cloud leaders, such as AWS, Google, and Microsoft. They support the three types of prediction: binary prediction, category prediction, and value prediction. The binary prediction type of ML prediction deals with "yes" or "no" answers. It is primarily used to detect fraud for referral mechanisms and order processing.

The category prediction implies that a data set is observed, and based on the data collected from the set, the data set is assigned to a particular category. For example, insurance companies use category prediction to classify different types of claims. In value prediction, patterns within accumulated data are found using learning models to demonstrate the quantitative measure of all likely outcomes. Companies use it to predict the approximate number of units of products sold shortly (e.g., next month). They are allowed to shape their production plans accordingly. In addition to these predictions, there are also the following learning types: supervised learning and unsupervised learning [23].

Supervised learning implies that an algorithm is given the data from which it learns and desired expressions. The algorithm should learn how to provide appropriate expressions for appropriate data, i.e., the program's task is to "learn" how to assign a correct output value to a new, unmarked input data. The ability to name the data that includes many preparation models is encouraged. Unsupervised learning is an ML algorithm used to draw inferences from the data sets, consisting of information without marked reactions. The best-known form of unsupervised learning is cluster analysis, which analyses information to reveal hidden examples or groupings within information [25].

\subsection{Enhancing Teaching and Learning in HEI}

Despite teachers, researchers, managers, and students all facing perennial problems, new approaches to problems faced by these three groups are being developed with the assistance of AI and ML [26]. First, the teaching workforce's quality should be improved to raise educational standards. Second, to achieve a higher standard of learning, it is critical to identify the factors contributing to teachers' workload. Third, teacher performance management is critical for effectively achieving the goals and objectives of high-quality educational standards. It is an ongoing process for identifying, evaluating, and developing teacher performance.

A McKinsey study conducted in 2017 showed that teachers work an average of $50 \mathrm{~h}$ a week [27], but they spend less than half of the time directly interacting with students. Future studies show that between $20 \%$ and $40 \%$ of teacher time is spent on activities that could be automated using available technology. This equates to about $13 \mathrm{~h}$ per week that teachers could devote to improving student outcomes and teacher satisfaction. Our findings indicate that most of the time spent by teachers can be reallocated to activities that promote student learning [28].

Teachers deal with this area before even entering the classroom: preparation. On average, teachers spend $11 \mathrm{~h}$ a week prepping. The use of technology could get it done 
in six hours or less. Even if teachers prepare the same amount of time, technology could produce better lesson plans and teaching approaches. However, technology has the least potential to save teacher time in activities where teachers have the most direct interaction with students: instructing and advising and coaching and counselling [29].

Despite being pioneers in academia when it comes to research and development in computer science, universities have thus far been unable to successfully utilise these technologies in several other facets of their operations. For example, the University of Derby introduced a system that monitors data to predict when students are likely to drop out to alert school staff to intervene at the earliest opportunity, and Professor Ashok Goel at Georgia Tech developed Jill Watson, an AI teaching assistant that students can interact with [7].

A component of an IP-enabled socio-technological system was created and implemented with Watson by Jill Watson for the Jill Watson Q\&A project (also known as Jill for short). Jill wants to create an online environment that helps teachers and students. On the other hand, using AI software for routine questions frees up valuable instructional time for instructors overburdened with other responsibilities. During this class period, the teacher can do any of the following: improve overall education quality, reduce per-student cost, or engage more students. Thus, Jill provides instructional support while making education more accessible by answering questions quickly and offering instructional support.

In order to classify Jill Watson Q\&A [7], the novel uses two-stage classification process. At the outset, ML classifiers, including Watson, LEX, and Auto ML, are used to identify different ML algorithms. They have our in-house, knowledge-based categorisation algorithm that is made use of in the second stage. The resulting results are the result of an algorithm that combines data-driven AI and ML. ML classifies a sentence, and knowledgebased AI extracts specific data from the resulting classification. The curriculum response evaluations are based on a detailed review of the course curriculum. This is based on the latest findings, which found that students respond positively to "human-like" actors. The student will also be taught signals (via cues) to draw the conversation into Jill's expertise if Jill cannot answer.

Regarding Jill Watson's Q\&A learning, Jill Watson's use of educational internet resources and learning programs are customised to fit everyone's needs, and Jill Watson's ability to do this on the internet is via educational websites. Jill Watson's work facilitates the formation of micro-communities by connecting students participating in asynchronous learning regardless of where they are geographically located. The Q\&A session provided by Jill Watson furthers student engagement. Instant feedback is associated with increased commitment, involvement, and improved performance in teachers, staff, and AI workers [7].

Based on quasi-experimental studies, online students who take classes in AI demonstrate the same levels of learning-assessment performance and completion rate as their peers enrolled in classes for that same subject area, which are offered online and in-person. Even with different student demographics taken into consideration, this conclusion stands firm [7]. A survey of online AI students revealed that they gain an increased perception of teaching support even when they are unaware of the existence of a fake teacher [29].

These case studies show that universities should be empowered to investigate the following topics:

- At what point should they employ AI (short or long term);

- Where AI has the most significant potential benefit;

- Ways to protect the privacy of students as they use data to help them; and

- When it comes to implementing AI, what do universities consider to be a success?

AI will open up many educational opportunities for higher education, and institutions that make the investment necessary to utilise it will realise significant benefits. Popenici and associates found that the use of technology or teacher bots in higher education is an increasingly attractive solution as enrolment increases, and class sizes, staffing costs, and finances for universities grow. This became evident when massive open online courses (MOOC) enlightened the imagination of many university administrators. With these "open 
courses," there are no enrolment requirements or fees, and online students from anywhere in the world could enrol and participate. These two forces were a boon to universities in that they allowed them to market globally for students, leading to an enormous number of new students. However, it quickly became apparent that one of the problems would prevent the agreement from going through. Nevertheless, HEI can use AI and ML for institutional purposes.

Algorithms are increasingly used in schools to market prospective students, estimate class size, plan curriculum, and allocate resources, like financial aid and facilities. AI and ML can help students, which is becoming more common in higher education. Schools use machine learning to help students. Some apps help students automatically schedule classes. Others, like guidance counsellors or career services offices, suggest courses, majors, and career paths. Financial aid is another area where AI can help students. Colleges and universities can use AI in education. They are creating systems that adapt to users' pace and progress. AI and ML can automatically help users tailor different paths or provide feedback based on their errors. Researchers in learning science can use this data to determine which pedagogical approaches, curricula, or interventions work best for which students. Many students worldwide and from different time zones gather from around the globe and are at different paces of learning. It requires a great deal of progress with different lenses and foundational skills to get through the course. As a result, they research advancing students in significant lecture classes' and learners' way of accomplishing their tasks, doing assessments, and feedback on unsolved issues [29].

Higher-quality college education can be delivered in a personalised and upgraded setting.

Admissions officers are having difficulty meeting fall enrolment targets. It can be assumed that this situation will not soon change. Over the past few years, the number of people who evaluate the benefits of studying and its cost has increased. As a result, people have an increased interest in the value of college compared to the return on investment. Students also worry about incurring debt. This has discouraged many people from applying. The sheer number of print and digital communications that prospective students receive ultimately leads to a situation where prospective students are flooded with many college communications. To both the student and the institution, this can be overwhelming.

Universities faces many difficulties when it comes to enrolling students, planning a curriculum, teaching students personalised lessons, and combating high dropout rates. Even if it is done manually, dealing with these difficulties can be overwhelming. One way to ensure institutional success is to use data analytics and AI in education and promote its use correctly. These colleges and universities have created chatbots designed to engage individual students and dig up applicant data and have built virtual teaching assistants using this data. Several educational and technological leaders are now using AI to take on tedious, repetitive tasks and offer a more engaging learning experience. They will soon be joined by the rest of them as well. After that, colleges and universities can use AI and ML to automate their daily operations. For example, when schools seek prospective students, ML can be viewed in several ways. AI is an excellent example of the type of technology that might replace workers in call centres, where automation would increase productivity [30].

Students have also received access to AI chatbots to find additional student services [31]. Introducing chatbots to academic settings in stages has the potential to be beneficial, as the tools' AI-based responses grow more refined over time. Another excellent example of this would be Martha, a bot developed by George Washington University, who engages in approximately 4500 conversations every month. Martha's engine is the BMC Helix Digital Workplace platform, leveraging IBM Watson Assistant conversational interface functionality. Before last year's pilot of MARTHA, George Washington University students had to call, email, or visit a walk-in centre on the Washington, DC, campus to get IT questions answered. The first time Professor Ashok Goel from Georgia Institute of Technology's School of Interactive Computing used AI as a teaching assistant, he used it to assist in his online course. He refrained from introducing her until the end of the course to 
avoid influencing her opinion. As a result, the students did not know that Jill was not a human being [28].

Students can use adaptive learning technology to customise their educational pathways [32]. Many universities believe that AI holds the potential to facilitate adaptive learning and boost student success. While this technology is widely used, most people are not using it because it has not penetrated their daily lives. At the same time, however, education is only just getting started. Most advanced techniques create a learning path when the student interacts with the system. Once the tools are in place, they can measure and respond to student progress on a moment-to-moment basis, using students' actual activities, analytical learning data, and ML. As a result, they can help each student using scaffolding to help them understand new concepts and help them succeed. This option is provided by the tools and data needed to provide feedback on the student's progress delivered asynchronously [33].

\section{Materials and Methods}

The researchers used the methodology that includes observations, participation observation, and a case study model. Additionally, document analysis was utilised. In addition, survey research among students (former, current, future) was conducted. This was done to get a general sense of how much knowledge of $\mathrm{AI}$ and ML is held by the student population and, in particular, to understand both opportunities and challenges involved in AI and ML in HEI. Survey research was conducted according to the model presented in the paper "AI in Higher Education: Promises, Perils, and Perspective" [34].

We used observation and observation with the participation method because we are all university professors involved in learning processes and daily interaction with students. Literature analysis or document analysis is also suitable for social sciences and getting information within secondary research to compare our findings and enrich them with relevant perspectives. A survey is an appropriate tool for gettering information that can be used for quantitative analysis and testing hypotheses. It is considered to be a low-cost tool in its digital (online) form as well as valuable for the importance of identifying people who use technological tools efficiently.

We have maintained objectivity and avoided bias with qualitative data analysis: using multiple people to code the data allowed participants to review our results. We used different statistical analyses so that we can be sure of the results. A wealthy literature review helped us verify our findings with more data sources and search for alternative explanations.

\subsection{Data and Variables}

Given that the data of 103 students from Serbia, Information Technology School ITS- Belgrade, were analysed, this is exploratory research. Therefore, the results obtained cannot be extrapolated to the entire statistical population (all students from Serbia) but represents preliminary and fundamental research for the second stage-exhaustive, new research on a representative sample. This research did not restrict the sample because it considered that technologies that favour learning should be transversal to different ways of learning.

We considered ten variables presented in Table 2. The rationale for considering these variables is to provide the best fit for the model so that accurate predictions can be made. Additionally, these variables were used in research that we used as a starting point [34]. 
Table 2. Variable analysed.

\begin{tabular}{cc}
\hline Code & Variable Name \\
\hline AI1 & AI and ML can enhance customised learning \\
\hline AI2 & AI and ML can develop skills among students \\
\hline AI3 & AI and ML are capable of providing a collaborative learning environment in the HEI \\
\hline AI4 & AI and ML can help in keeping lifelong connectivity with alumni \\
\hline AI5 & AI and ML have much potential in improving the institution's security \\
\hline AI6 & AI and ML have much potential in improving the institution's efficiency \\
\hline AI7 & AI and ML allows sharing and storing a large amount of data \\
\hline AI8 & $\begin{array}{c}\text { AI and ML provide researchers with a peaceful, flexible, and accessible computing } \\
\text { environment, thereby letting them focus on research without any constraints }\end{array}$ \\
\hline AI9 & AI and ML provide researchers with an accessible research environment \\
\hline Age & Age \\
\hline Activity & Type of activity \\
\hline AIUSE & $\begin{array}{r}\text { AI represents the theory and development of computer systems able to perform tasks } \\
\text { normally requiring human intelligence, such as visual perception, speech recognition, } \\
\text { decision making, and translation between languages. }\end{array}$ \\
\hline AIDEF & AI and ML are opportunities \\
\hline AIOC &
\end{tabular}

\subsection{Research Process}

The literature review emphasises some opportunities and challenges associated with $\mathrm{AI}$ and ML in HEI. This fact urged us to make an exploratory reach in Serbia regarding the effects of AI and ML implementation in HEI. Keeping in mind that the young generation represents our future and is very keen on technology, we designed a survey to help Serbian HEI managers/authorities adopt and implement AI and ML in the HE Serbian system. The student survey research is conducted in Information Technology School ITS-Belgrade, to collect data from quantifying the state of the HEI student population's knowledge of AI and ML while also researching their opportunities and challenges in AI and ML. According to the findings on AI outlined in the paper mentioned above, in AI in Higher Education: Promises, Perils, and Perspectives," an academic research survey was conducted [34].

We address the following critical issues in this article:

1. Common knowledge and stance of research bases regarding AI and ML in HEI;

2. Best practices regarding usage of $\mathrm{AI}$ and ML in HEI;

3. Students' knowledge of AI and ML; and

4. Students' attitudes regarding AI and ML opportunities and challenges in HEI.

Our analysis starts from the following assumption:

Hypothesis 1 (H1). AI and ML are essential technologies enhancing learning, primarily through students' skills, collaborative learning in HEI, and providing researchers with an accessible research environment.

Within the research process, we selected and coded variables that can answer H1.

Different analytical tools and applications were used to code the data and extract knowledge (Tables 2 and 3, Figure 1), including correlation matrix, composite reliability, and regression model. First, the variables were mined with Smart-PLS3 [35,36]. Then, after correlating data, coding the variables, and verifying the reliability model, we designed a regression model assuming $\mathrm{H} 1$. 
Table 3. Correlation between variables.

\begin{tabular}{|c|c|c|c|c|c|c|c|c|c|c|c|}
\hline & AGE & ACTIVITY & AI1 & AI2 & AI3 & AI4 & AI5 & AI6 & AI7 & AI8 & AI9 \\
\hline AGE & 1.00 & & & & & & & & & & \\
\hline ACTIVITY & 0.61 & 1.00 & & & & & & & & & \\
\hline AI1 & -0.13 & 0.06 & 1.00 & & & & & & & & \\
\hline AI2 & -0.11 & 0.00 & 0.72 & 1.00 & & & & & & & \\
\hline $\mathrm{AI} 3$ & -0.12 & 0.02 & 0.76 & 0.74 & 1.00 & & & & & & \\
\hline AI4 & -0.02 & 0.00 & 0.50 & 0.58 & 0.68 & 1.00 & & & & & \\
\hline AI5 & -0.10 & -0.04 & 0.59 & 0.57 & 0.59 & 0.60 & 1.00 & & & & \\
\hline AI6 & -0.14 & -0.03 & 0.62 & 0.60 & 0.58 & 0.45 & 0.70 & 1.00 & & & \\
\hline AI7 & -0.26 & -0.10 & 0.46 & 0.51 & 0.51 & 0.43 & 0.60 & 0.46 & 1.00 & & \\
\hline AI8 & -0.22 & -0.01 & 0.64 & 0.62 & 0.64 & 0.54 & 0.59 & 0.58 & 0.56 & 1.00 & \\
\hline AI9 & -0.18 & 0.10 & 0.67 & 0.54 & 0.68 & 0.53 & 0.60 & 0.64 & 0.56 & 0.81 & 1.00 \\
\hline
\end{tabular}

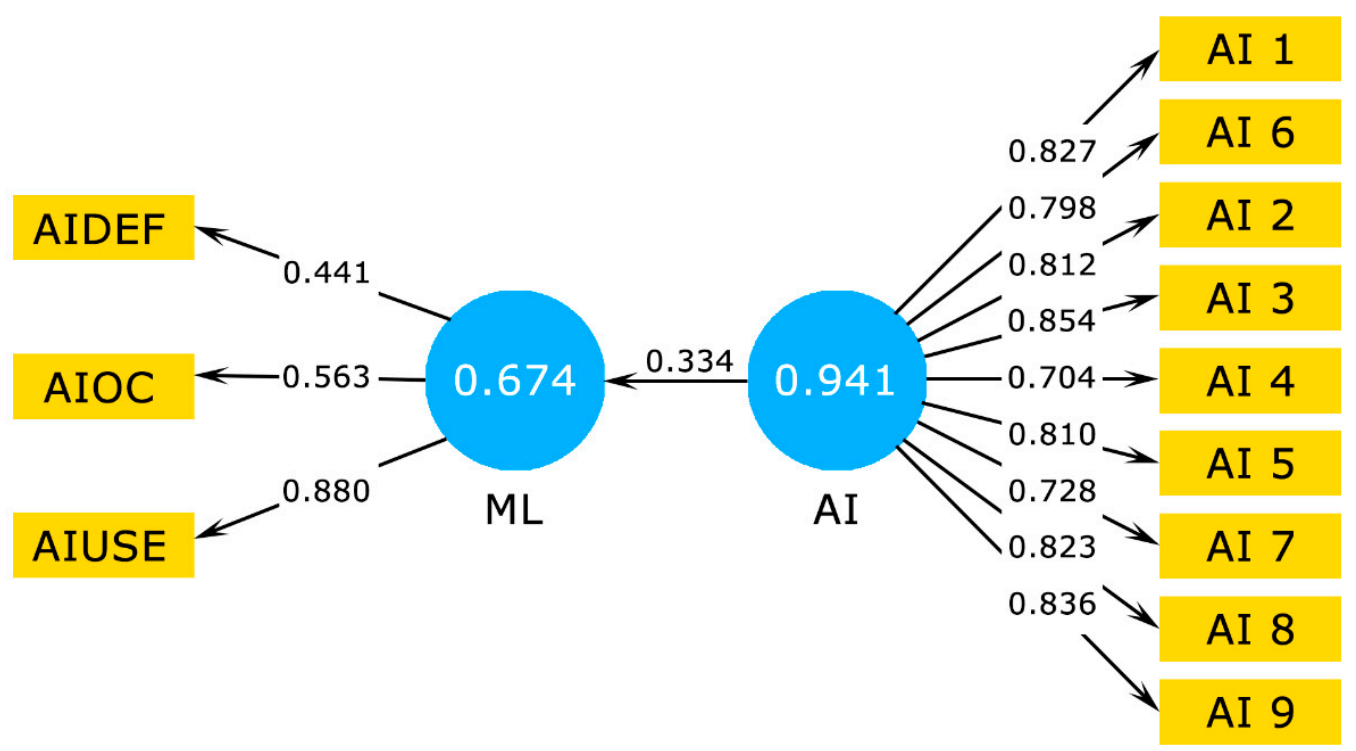

Figure 1. Composite Reliability Model.

The lack of research in the field of usage of AI and ML on university students (in total), especially in the Republic of Serbia, is the primary motive for this research and its added value.

\section{Results}

In statistical considerations, aiming to evaluate if the indicators were considered reflexive and, in this case, belong to the same theoretical dimension, the Correlation Matrix was utilized and is presented, followed by the Composite Reliability. Finally, the results were evaluated by regression analysis.

\subsection{The First Stag-Correlation Matrix Results}

Our analysis shows a powerful correlation between AI1 and AI2 and AI3, AI5 and AI6, and AI8 and AI9. These correlations let us assume that AI and ML can enhance customised learning in many ways: developing skills among students; providing a collaborative learning environment in the HEI; providing potential in improving the institution's security and efficiency; providing researchers with a peaceful, flexible, and accessible computing environment, thereby letting them focus on research without any constraints; and providing researchers with accessible research environment. Furthermore, another strong correlation between age and activity might be observed, revealing that young students are very enthusiastic about using AI and ML in their learning activity (Table 3). 


\subsection{The Second Stage-Composite Reliability}

Composite reliability is a conservative to validate if there is an overall factor of the indices and, consequently, a theoretical dimension to the construct [37]. The composite reliability can be verified through the beta coefficient [38] of internal consistency, which should be higher than 0.70 , and reliability alpha [39], which should be higher than 0.80 . Values above 0.7 are already indicative of a reliable reflective measurement [40]. Loadings of 0.5 or 0.6 may be acceptable if additional indicators are available for a basis of comparison [41]. However, when their loadings are less than 0.4, reflective indicators should be eliminated [42]. The correlation between the indicators can also assess the reflective measures of the constructs. The empirical tests suggested by Coltman [43] included (i) internal consistency, (ii) reliability, (iii) factor average variance extracted (AVE), and (iv) factor loadings. Table 4 shows these values.

Table 4. Validation Process.

\begin{tabular}{cccccc}
\hline \multirow{2}{*}{$\begin{array}{c}\text { Reflexive } \\
\text { Construct }\end{array}$} & $\begin{array}{c}\text { Composite } \\
\text { Reliability }\end{array}$ & $\begin{array}{c}\text { Alpha } \\
\text { Cronbach }\end{array}$ & AVE & $\sqrt{ }$ AVE & $\begin{array}{c}\text { Factor } \\
\text { Loading }\end{array}$ \\
\cline { 2 - 6 } & $\mathbf{( > 0 . 7 )}$ & $\mathbf{( > 0 . 7 )}$ & $\mathbf{( > 0 . 5 )}$ & $\mathbf{( > 0 . 5 )}$ & $\mathbf{( > 0 . 5 )}$ \\
\hline AI & 0.941 & 0.930 & 0.641 & 0.800624756 & 0.941 \\
\hline ML & 0.674 & 0.380 & 0.428 & 0.654217089 & 0.674 \\
\hline
\end{tabular}

The composite reliability shows a very strong model because all the values of the AI factors (sub-indices) are very high (more excellent than 0.7). However, for the ML variable, the reliability is good (0.67) but not strong enough. Therefore, we will not include it in the regression model.

There are two criteria for analysing the discriminant validity of reflective measures: the Fornell-Larcker criterion (1981) and the cross-loading of the indicators [44,45]. According to the Fornell-Larcker criterion in 1981, discriminant validity is obtained when the square root of each construct's average variance extracted (AVE) is greater than the correlation with all other indicators $[44,45]$. Indicators AI6, AI4, and AI5 did not fit the first criterion of discriminant validity and AIDEF and AIOC. The bootstrapping procedure to identify the Variance Inflation Factor (VIF) of each construct was performed with 5000 samples and a reliability of $95 \%$ with the help of SPSS software, as suggested by Hair and Ringle [44]. The results are summarised in Table 5. Considering the significance of $5 \%$ for the two-tailed test in bootstrapping, $t$-values below 1.96 are considered critical [44]. In this case, all values were considered significant. The existing sensitivity to sample size can be validated by the value of the factorial inflationary variance, which ensures the variance stability when it is less than 5 [46].

Table 5. Validation Process through Bootstrapping of 5000.

\begin{tabular}{cccccccccccc}
\hline \multicolumn{1}{c}{ AI } & \multicolumn{1}{c}{ ML } \\
\hline AI1 & AI2 & AI3 & AI4 & AI5 & AI6 & AI7 & AI8 & AI9 & AIUSE AIDEF AIOC \\
\hline 17.28 & 16.13 & 12.69 & 23.76 & 8.54 & 20.04 & 9.55 & 17.65 & 22.29 & 7.98 & 2.17 & 2.46 \\
$\left(^{*}\right)$ & $\left(^{*}\right)$ & $\left(^{*}\right)$ & $\left(^{*}\right)$ & $\left(^{*}\right)$ & $\left({ }^{*}\right)$ & $\left(^{*}\right)$ & $\left(^{*}\right)$ & $\left(^{*}\right)$ & $(*)$ & $\left(^{*}\right)$ & $\left(^{*}\right)$ \\
\hline
\end{tabular}

(*) Sig of 0.05 .

\subsection{The Third Stage-Regression Model Results}

The interpretation above is supported by the model below. In the regression model, we may observe that $\mathrm{AI}$ and ML are essential technologies enhancing learning, primarily through students' skills, collaborative learning in HEI, improving the institution's security and efficiency, and providing a good research environment. Overall, the model is representative ( $R^{2}$ is 0.648$)$, meaning that AI brings many benefits in HEI. The variation of the independent variable (AI2, AI3, and AI9) explains $67 \%$ of the variation of the dependent 
variable (AI1). The other percentages should be explained by other variables, such as AI4, AI5, AI6, AI7, AI8, and other factors, such as teaching methodologies, macro-economic evolutions (economical-social context).

The ANOVA test confirms the before-mentioned findings because $\mathrm{F}>\mathrm{F}$ crit and Sig $\mathrm{F}<0.01$. In addition, the ANOVA test assumptions are met: the dependent variable is measured on a continuous scale; the independent variables are made of four different categorical, independent groups; the observations are independent (which means that there is no relationship between the observations of each group or between the groups themselves); there are no extreme values; the variable is distributed generally in each group of the independent variable; and there is a homogeneity of variants (Table 6).

Table 6. Regression Model.

\begin{tabular}{|c|c|c|c|c|c|c|}
\hline \multicolumn{7}{|c|}{ Regression Statistics } \\
\hline Multiple R & 0.81893 & & & & & \\
\hline R Square & 0.67064 & & & & & \\
\hline Adjusted R Square & 0.66066 & & & & & \\
\hline Standard Error & 0.63739 & & & & & \\
\hline Observations & 103 & & & & & \\
\hline ANOVA & df & SS & MS & $\mathrm{F}$ & Significance F & \\
\hline Regression & 3 & 81.8965 & 27.299 & 67.2 & $9 \times 10^{-24}$ & \\
\hline Residual & 99 & 40.22 & 0.4063 & & & \\
\hline Total & 102 & 122.117 & & & & \\
\hline Coefficients & & Standard Error & t Stat & $p$-value & Lower 95\% & Upper 95\% \\
\hline Intercept & 0.14444 & 0.2993 & 0.4826 & 0.63 & -0.449 & 0.7 \\
\hline $\mathrm{AI} 2$ & 0.37258 & 0.09522 & 3.9127 & $2 \times 10^{-4}$ & 0.1836 & 0.6 \\
\hline AI3 & 0.345 & 0.10418 & 3.3116 & 0.001 & 0.1383 & 0.6 \\
\hline AI9 & 0.28908 & 0.08588 & 3.3662 & 0.001 & 0.1187 & 0.5 \\
\hline
\end{tabular}

The Multiple $\mathrm{R}$ coefficient is 0.818 has a high value. The $p$-value shows Prob (F-statistic), representing the F-test marginal significance level. In the case of a $p$-value less than 0.05 (significance level), H1, the alternative hypothesis, is accepted. The new model results can be seen in Table 5. The $p$-value takes values smaller than 0.01 (less than the sensitivity threshold of 0.05 ) for AI2, AI3, and AI9, with a very high probability of guaranteeing results, meaning that the coefficients of this variable are very well estimated. Overall, the model is reliable. (Table 5). The $R^{2}$ coefficient of this model is 0.818 and indicates that the variation of causal variables determines $82 \%$ of the AI1 variable variance, and the model cannot explain $18 \%$ of this influence.

Following the statistical $t$-test, the resulting coefficient for the AI2 variable was 0.37, with a low standard error (0.09), and with $95 \%$ likelihood, it will be found in the interval $(0.18 ; 0.6)$. The coefficient for the AI3 variable is 0.34 with a low standard error $(0.1)$, and with $95 \%$ likelihood, it will be found in the interval $(0.14 ; 0.6)$. The coefficient for the AI9 variable is 0.28 with a low standard error $(0.08)$, and with $95 \%$ likelihood, it will be found in the interval $(0.12 ; 0.5)$. The coefficient for Intercept is 0.14 with a probability of guaranteeing results ( $p$-value) of 0.063 greater than 0.05 , meaning that this coefficient is not very well estimated. This coefficient will be found in the interval $(-0.45 ; 0.7)$ with $95 \%$ likelihood. Thus, the $t$-test for each variable generated validates the model and contributes to the predictive power of the regression. The significance threshold of the variables should be less or around 0.05 (Table 6). In conclusion, following the above results, we can state that regression analyses confirmed our hypothesis.

The regression equation is

$$
\mathrm{AI} 1=0.14+0.37 \times \mathrm{AI} 2+0.34 \times \mathrm{AI} 3+0.28 \times \mathrm{AI} 9
$$

\section{Discussion and Further Recommendations}

Assuming the hypothesis remains valid because the variables and the reliability of the model were checked considering that AI and ML are technologies that improve the safety 
and efficiency of the institution and contribute to learning, this leads to the assumption that the strong correlation between AI and ML can enhance customised learning (AI1). For example, digital algorithms were evidenced to improve medical care [21,22]. Furthermore, according to Shah [21], strategies can be created by integrating AI- and ML-based digital methods and secure computing technologies.

Our analysis reveals a strong correlation between $\mathrm{AI} 1$ and $\mathrm{AI} 2, \mathrm{AI} 3$ and AI5, and AI6 and AI8 and AI9. These correlations lead us to believe that AI and ML can enhance individualised learning in a variety of ways: by developing students' skills; providing a collaborative learning environment within the HEI; potentially improving the institution's security and efficiency; and providing researchers with a peaceful, flexible, and accessible computing environment that allows them to focus exclusively on research. Additionally, a strong correlation between age and activity can be observed, indicating that young students are highly enthusiastic about incorporating $\mathrm{AI}$ and machine learning into their learning activities.

The strong correlations pointed out that AI and ML can develop skills among students (AI2) [20] as well as provide a collaborative learning environment in the HEI (AI3) [1]. In other words, through skills development and collaborative learning [30], AI and ML can enhance customised learning [2].

The strong correlations between a peaceful, flexible, and accessible computing environment (AI8) and an accessible research environment (AI9) point to a research-friendly environment. Furthermore, AI and ML can improve the institution's security (AI5) and efficiency (AI6). Besides that, considering the strong correlation between age and activity is suggested, indicating that young students are very enthusiastic about using AI and ML in their learning activity.

We can see from the regression model that $\mathrm{AI}$ and machine learning are critical technologies for enhancing learning, primarily through students' skills, collaborative learning in HEIs, enhancing the security and efficiency of the institution, and providing a conducive research environment. In general, the model is representative $(\mathrm{R} 2=0.648)$, indicating that AI has numerous benefits for HEI. The independent variables (AI2, AI3, and AI9) account for $67 \%$ of the variation in the dependent variable (AI1). The remaining percentages should be explained by additional variables, such as AI4, AI5, AI6, AI7, and AI8, and other factors, such as teaching methodologies and macroeconomic changes (economical-social context).

Improving the security and efficiency of the institution; providing a peaceful, flexible, and accessible computing environment for research; and developing skills among students and a collaborative learning environment in the HEI reinforce the importance of AI and ML to enhance customised learning [8].

Students prefer to use new technologies in education due to the high level of interactivity, the requirement for motivation and enthusiasm, and the opportunities for experimentation and simulation, as demonstrated by research from Serbia, Romania, and Hungary. Universities must embrace these technologies and develop new methods of training and teaching to meet the expectations of millennials and the technological revolution [47]. Research from Romania among students showed that students favour that immersion of cutting edge technologies like virtual reality (VR) and augmented reality (AR) in the process of presenting information and knowledge acquisition, and these can be considered as a method to improve the quality of higher education [48].

\section{Conclusions}

College students today have an excellent opportunity to learn in an interactive and personalised setting. AI, in particular, is capable of assisting with both of these issues. AI, fed and learned from big data, can provide students with individualised learning experiences. Simultaneously, professors can discover new ways different students learn and advise them on tailoring their teaching methods to meet their needs.

Colleges, universities, and other educational institutions and EdTech companies can benefit more from these technologies if they are willing to try new approaches and, as 
a result, gain a competitive advantage. If these institutions are eager to implement AI methods, they will meet the increasing demand for adaptive and personalised education. Adopting a data science approach centred on ML as a tool is an exciting new way to promote AI and ML in higher education.

Many industries are experiencing revolutions and evolutions due to $\mathrm{AI}$ and ML, and we are witnessing these changes first-hand. Unfortunately, this rule does not apply to higher education. This ground-breaking study in the field offers valuable insights and perspectives on higher education in the age of AI. The higher education system has suffered greatly during these turbulent times. Colleges and universities have been grappling with enrolment and funding issues due to the pandemic's spread, which is still difficult to combat in some parts of the world. However, many institutions, universities, and colleges have always wanted to be innovative to ensure their survival and improve their students' daily experiences.

Although AI is a relatively new and rapidly evolving technology, it can be found in various, well-established fields of science, including computer science, psychology, language science, philosophy, statistics, mathematics, and electrical engineering. AI is becoming increasingly important, as financial and enrolment pressures in higher education become more prevalent. This has necessitated the development of low-cost technologies capable of providing students with personalised support and service. For example, chatbots and other instant self-service technologies can enable higher education institutions to be more innovative. Furthermore, using the most recent AI and ML methodologies enables the development of new technological innovation equivalent to ten years of work in a relatively short time. The use of AI is critical to providing a more consistent and accessible customer experience. However, there are some constraints regarding its use in sectors such as healthcare, where ethics play a crucial role, mainly due to the difficulty of preserving human individuality before society or its black-box model.

Nevertheless, AI that is both accessible and affordable can provide much hope. AI is currently occupying the "smaller" end of the AI spectrum. Nonetheless, if done correctly, the impact and depth will grow over time. Regarding the lessons learned, a significant contribution of this study lies in addressing the opportunities and challenges of AI and ML implementation in HEIs in middle-income countries and lessons that can be applied in this context.

Closing the research gap, as formulated after the literature review, is how to overcome the challenges of AI and ML implementation in HEI. Good recommendations applicable to low- and middle-income countries especially are insufficient in the available literature.

Every research, and this one is no exception, has limitations. This research's limitations are due to social desirability, generalizability, imprecise measures, and unasked questions. Keeping in mind that this is an original research paper and not a review paper, acknowledging the past related work in the reference list must be limited. Nevertheless, recommendations for future research that builds on this study's findings must be included. Therefore, future research must be directed at proposing concrete AI and ML platforms and projects for HEIs, especially in low- and middle-income countries, and promoting best practices that, once accepted, could help HEIs most effectively overcome the challenges they face.

Author Contributions: Conceptualisation, V.K., M.I., M.D. and O.M.D.M.; methodology, V.K., M.D., M.I. and D.P.; software, M.D.; validation, O.M.D.M., D.P., V.K. and M.I.; formal analysis, V.K.; investigation, V.K., M.I., M.D. and D.P.; resources, V.K., M.D., L.M. and M.I.; data curation, O.M.D.M. and M.R.; writing—original draft preparation, V.K., M.D., M.I. and L.M.; writing-review and editing, O.M.D.M., M.R., D.P. and V.K.; visualisation V.K., M.I. and M.R.; supervision, M.D. and V.K.; project administration, D.P. and M.I. All authors have read and agreed to the published version of the manuscript.

Funding: This research received no external funding.

Informed Consent Statement: Informed consent was obtained from all subjects involved in the study. 


\section{Data Availability Statement: Not applicable.}

Conflicts of Interest: The authors declare no conflict of interest.

\section{References}

1. Asthana, P.; Hazela, B. Applications of Machine Learning in Improving Learning Environment. In Multimedia Big Data Computing for IoT Applications; Tanwar, S., Tyagi, S., Kumar, N., Eds.; Intelligent Systems Reference Library; Springer: Singapore, 2020; Volume 163. [CrossRef]

2. Liu, S.; Chen, Y.; Huang, H.; Xiao, L.; Hei, X. Towards Smart Educational Recommendations with Reinforcement Learning in Classroom. In Proceedings of the 2018 IEEE International Conference on Teaching, Assessment, and Learning for Engineering (TALE), Wollongong, Australia, 4-7 December 2018; pp. 1079-1084. [CrossRef]

3. National Body for Accreditation and Quality Assurance in Higher Education (NAT). 2021. Available online: https://www.nat.rs/ (accessed on 1 July 2021).

4. Radić, G.; Ristić, B.; Anđelić, B.; Kuleto, V.; Ilić, M. E-learning Experiences of higher education institutions in the Republic of Serbia during COVID-19, content analysis and case study ITS Belgrade. Sustainable Economic Development and Advancing Education Excellence in the era of Global Pandemic. In Proceedings of the 36th International Business Information Management, Granada, Spain, 4-5 November 2020; ISBN 978-0-9998551-5-7.

5. Chang, R. Report Artificial Intelligence to Grow 47.5\% in Education over Next 4 Years. 2017. Available online: https://thejournal. com/articles/2017/03/24/ai-market-to-grow-47.5-percent-over-next-four-years.aspx (accessed on 13 June 2021).

6. Lacity, M.; Scheepers, R.; Willcocks, L.; Craig, A. Reimagining the University at Deakin: An IBM Watson Automation Journey. The Outsourcing Unit Working Research Paper Series. 2017. Available online: http://www.umsl.edu/ \{\}lacitym/LSEOUWP1704.pdf (accessed on 8 June 2021).

7. Goel, A. AI-Powered Learning: Making Education Accessible, Affordable, and Achievable. 2020. Available online: https: / / arxiv.org/abs/2006.01908 (accessed on 8 June 2021).

8. Kumar, A. National AI Policy/Strategy of India and China: A Comparative Analysis; Research and Information System for Developing Countries: New Delhi, India, 2021.

9. O'Leary, Z. The Essential Guide to Doing Your Research Project; SAGE: London, UK, 2014.

10. Oxford Languages Artificial Intelligence Definition. Available online: https://languages.oup.com/google-dictionary-en/ (accessed on 13 June 2021).

11. Oxford Languages E-Learning Definition. Available online: https://www.oxfordreference.com/view/10.1093/oi/authority.2011 0803095745661/ (accessed on 13 June 2021).

12. IBM Machine Learning Definition. Available online: https:/ /www.ibm.com/cloud/learn/machine-learning (accessed on 12 June 2021).

13. IGI Global. What is Higher Education Institution? Available online: https://www.igi-global.com/dictionary/higher-educationinstitution/13096 (accessed on 7 September 2021).

14. Mosavi, A.; Faghan, Y.; Ghamisi, P.; Duan, P.; Ardabili, S.F.; Salwana, E.; Band, S.S. Comprehensive review of deep reinforcement learning methods and applications in economics. Mathematics 2020, 8, 1640. [CrossRef]

15. Sutton, R.S. Generalisation in reinforcement learning: Successful examples using sparse, coarse coding. In Proceedings of the Advances in Neural Information Processing Systems, Denver, CO, USA, 2-5 December 1996.

16. Ministère de l'Éducation et de l'Enseigment Supérieur. Digital Competency Framework. Québec: Gouvernement du Québec. 2019. Available online: http://www.education.gouv.qc.ca/fileadmin/site_web/documents/ministere/Cadre-reference-competencenum-AN.pdf (accessed on 12 June 2021).

17. Russell, S.; Norvig, P. Artificial Intelligence: A Modern Approach; Pearson: London, UK, 2003.

18. Charlesworth, A. Absolute Essentials of Digital Marketing; Routledge: London, UK, 2020.

19. Hassanien, A.; Darwish, A.; El-Aska, H. Machine Learning and Data Mining in Aerospace Technology; Springer Nature Switzerland AG: Cham, Switzerland, 2020.

20. SAS. The Artificial Intelligence of Things. White Paper. SAS Analytics Solutions. 2020. Available online: https: //www.sas.com/content/dam/SAS/documents/marketing-whitepapers-ebooks/sas-whitepapers/en/artificial-intelligenceof-things-110060.pdf (accessed on 12 June 2021).

21. Shah, P.; Kendall, F.; Khozin, S.; Goosen, R.; Hu, J.; Laramie, J.; Ringel, M.; Schork, N. Artificial intelligence and machine learning in clinical development: A translational perspective. Digit. Med. 2019, 2, 69. [CrossRef] [PubMed]

22. Gerke, S.; Babic, B.; Evgeniou, T.; Glenn, C. The need for a system view to regulate artificial intelligence/machine learning-based software as medical device. Digit. Med. 2020, 3, 53. [CrossRef] [PubMed]

23. Kuleto, V.; Ilić, M.; Popović Šević, N.; Hadžić, A. Machine learning in the Cloud and business transformation. New Trends. In Digital Transformation: Monograph; University “Union-Nikola Tesla": Belgrade, Serbia, 2021.

24. Pop, D. Machine Learning and Cloud Computing: Survey of Distributed and SaaS Solutions. 2012. Available online: https://www.researchgate.net/publication/257068169_Machine_Learning_and_Cloud_Computing_Survey_of_Distributed_ and_SaaS_Solutions (accessed on 11 June 2021).

25. Guo, H.; Wang, L.; Chen, F. Scientific Big Data and Digital Earth. 2014. Available online: https://www.researchgate.net/ publication/274233315_Scientific_big_data_and_Digital_Earth (accessed on 12 June 2021). 
26. Ilić, M.; Popović Šević, N.; Ristić, B. Integrating Human Resources and Customer Relationship Management for Student Satisfaction in Higher Education: Gaining a Competitive Advantage. In Proceedings of the International May Conference on Strategic Management (IMCSM), Bor, Serbia, 25-27 September 2020; pp. 501-508.

27. McKinsey Global Teacher and Student Survey. Average of Canada, Singapore, United Kingdom, and United States in 2017.2017. Available online: https:/ / www.mckinsey.com/industries/public-and-social-sector/our-insights/how-artificial-intelligencewill-impact-k-12-teachers (accessed on 20 August 2021).

28. Bryant, J.; Heitz, C.; Sanghvi, S.; Wagle, D. How Artificial Intelligence Will Impact K-12 Teachers; McKinsey and Company: New York, NY, USA, 2020; Available online: https:/ / www.mckinsey.com/industries/public-and-social-sector/our-insights/howartificial-intelligence-will-impact-k-12-teachers (accessed on 13 June 2021).

29. Gonzales, M.; Goel, A. Why Are Some Online Educational Programs Successful? A Cognitive Science Perspective. In Proceedings of the Poster Paper at the 41st Annual Meeting of the Cognitive Science Society, Montreal, QC, Canada, $24-27$ July 2019.

30. Popenici, S.A.; Kerr, S. Exploring the impact of artificial intelligence on teaching and learning in higher education. Res. Pract. Technol. Enhanc. Learn. 2017, 12, 22. [CrossRef] [PubMed]

31. EdTech Magazine. 2020. Available online: https://edtechmagazine.com/higher/article/2020/02/5-year-vision-artificialintelligence-higher-ed (accessed on 12 June 2021).

32. EdTech Magazine. 2019. Available online: https://edtechmagazine.com/higher/article/2019/12/ai-and-smart-campuses-areamong-higher-ed-tech-watch-2020-1 (accessed on 12 June 2021).

33. Taylor, D.L.; Yeung, M.; Bashet, A.Z. Personalised and Adaptive Learning. In Innovative Learning Environments in STEM Higher Education. SpringerBriefs in Statistics; Ryoo, J., Winkelmann, K., Eds.; Springer: Cham, Switzerland, 2021. [CrossRef]

34. Dhawan, S.; Batra, G. Artificial Intelligence in Higher Education: Promises, Perils, and Perspective; OJAS: New Delhi, India, 2021; pp. 11-22.

35. Ringle, C.M.; Wende, S.; Becker, J.M. SmartPLS 3 [Computer Software]. Bönningstedt. 2015. Available online: http://www. smartpls.com (accessed on 20 August 2021).

36. SmartPLS. Available online: https:/ / www.smartpls.com (accessed on 12 June 2021).

37. Sarstedt, M.; Ringle, C.M.; Hair, J.F. Partial Least Squares Structural Equation Modeling. In Handbook of Market Research; Homburg, C., Klarmann, M., Vomberg, A.E., Eds.; Springer International Publishing: New York, NY, USA, 2021; pp. 1-47.

38. Rossiter, J. The C-OAR-SE procedure for scale development in marketing. Int. J. Res. Mark. 2001, 19, 305-335. [CrossRef]

39. Revelle, W. Hierarchical clustering and the internal structure of tests. Multivar. Behav. Res. 1979, 14, 57-74. [CrossRef] [PubMed]

40. Churchill, G.A. A paradigm for developing better measures of marketing Constructs. J. Mark. Res. 1979, 16, 64-73. [CrossRef]

41. Gudergan, S.; Ringle, C.; Wende, S.; Will, A. Confirmatory tetrad analysis in PLS path modeling. J. Bus. Res. 2008, 61, 1238-1249. [CrossRef]

42. Chin, W.W. How to Write Up and Report PLS Analyses. In Handbook of Partial Least Squares: Concepts, Methods and Applications; Vinzi, V.E., Chin, W.W., Henseler, J., Wang, H., Eds.; Springer: Berlin/Heidelberg, Germany, 2010; ISBN 978-3-540-32825-4. [CrossRef]

43. Gotz, O.; Liehr-Gobbers, K.; Krafft, M. Evaluation of Structural Equation Models Using the Partial Least Squares (PLS) Approach. In Handbook of Partial Least Squares: Concepts, Methods and Applications; Vinzi, V.E., Chin, W.W., Henseler, J., Wang, H., Eds.; Springer: Berlin/Heidelberg, Germany, 2010; ISBN 978-3-540-32825-4. [CrossRef]

44. Coltman, T.; Devinney, T.M.; Midgley, D.F.; Venaik, S. Formative versus reflective measurement models Two applications of formative measurement. J. Bus. Res. 2008, 61, 1250-1262. [CrossRef]

45. Hair, J.F.; Ringle, C.M.; Sarstedt, M. PLS-SEM: Indeed a Silver Bullet. 2011. J. Mark. Theory Pract. 2011, 19, 139-152. [CrossRef]

46. Hair, J.F.; Sarstedt, M.; Ringle, C.M.; Mena, J.A. An assessment of the use of partial least squares structural equation modeling in marketing research. J. Acad. Mark. Sci. 2012, 40, 414-433. [CrossRef]

47. Bucea-Manea-Țoniş, R.; Bucea-Manea-Țoniş, R.; Simion, V.E.; Ilic, D.; Braicu, C.; Manea, N. Sustainability in Higher Education: The Relationship between Work-Life Balance and XR E-Learning Facilities. Sustainability 2020, 12, 5872. [CrossRef]

48. Bucea-Manea-T,oniş, R.; Manea, N. Quality parametres on higher education PhD program in Romania. Indep. J. Manag. Prod. 2019, 10, 2. [CrossRef] 